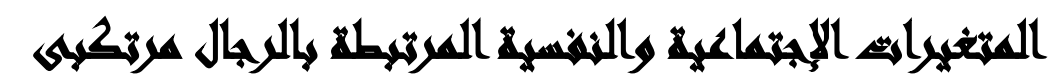

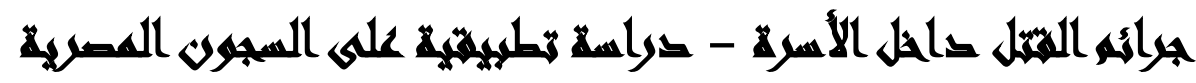

\section{[10]}

\author{
عُليه محمد عبدالمنعم(')- جمال شفيق أحمد(؟) - محمود عبدالحميا حسين(")

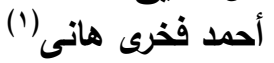

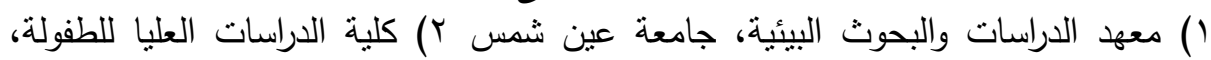

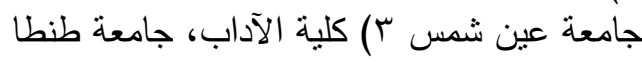

\section{المستخلئ}

هدفت الدراسة الحالية إلى إلقاء الضوء على الضى ارتكاب الرجال لجرائم القتل تجاه أفراد

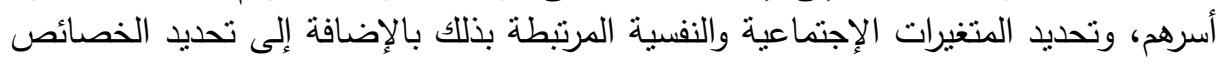

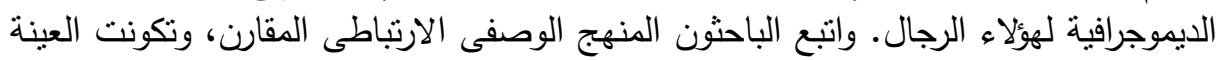

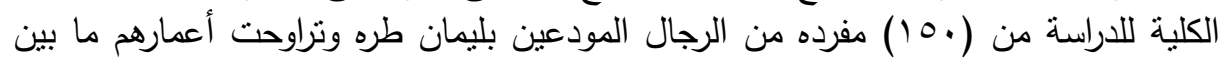

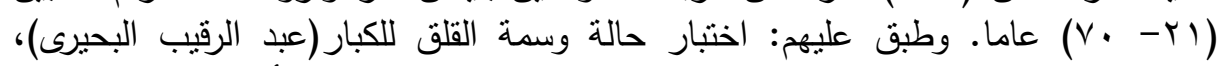

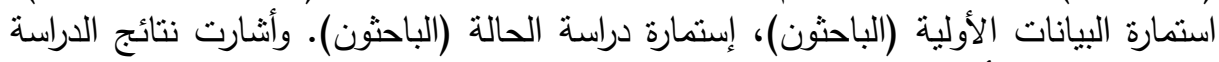

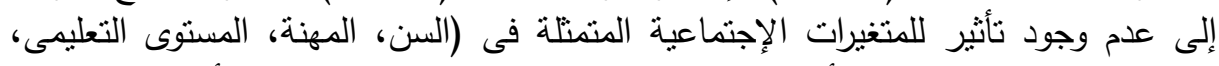

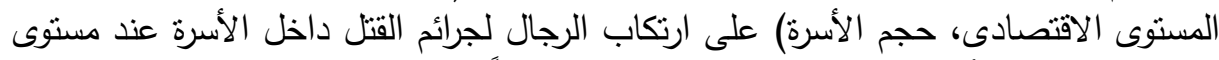

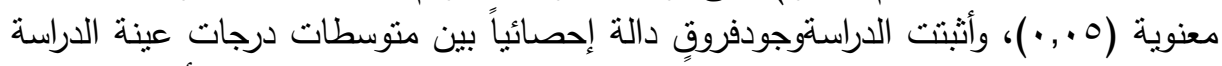

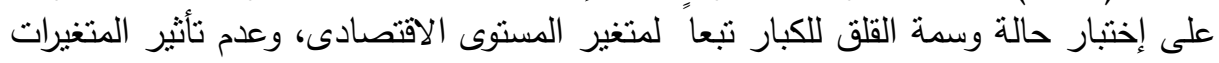

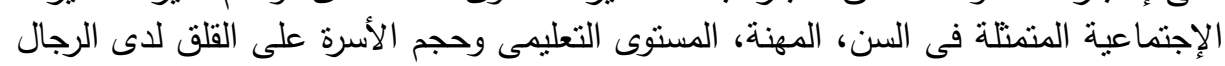

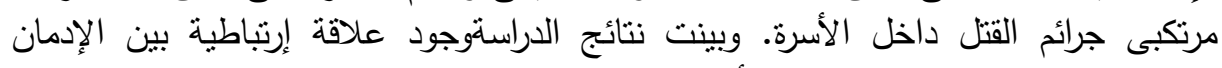
وارتكاب الرجال لجرائم القتل داخل الأسرة.

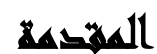

شهد المجتمع المصرى فى الآونة الأخيرة لاسيما عقب ثورتى الخامس والعثرين من

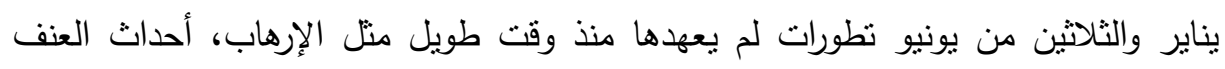

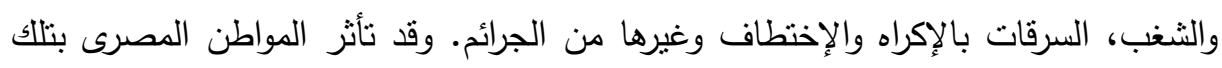

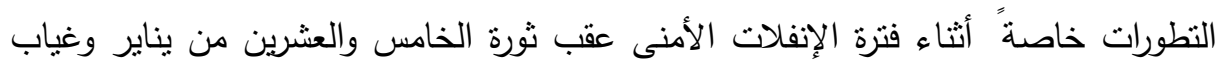
دور الشرطة مما دعا المواطن لحماية أسرتة وممتلكاتة بنفسه، وظهر ذلك واضحاً فئ الأنى اللجان

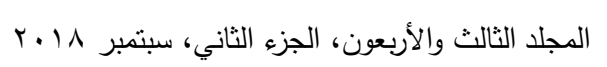


الثعبية التى كوَنها المصريين لحماية أنفسهر وممنلكاتهم بالإضافة إلى حماية المنشآت الحيوية

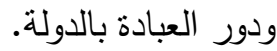

وعلى الرغم من الجانب الإيجابى للجان الثعبية (فى تلك الفترة) إلا أنها لها جانب آخر

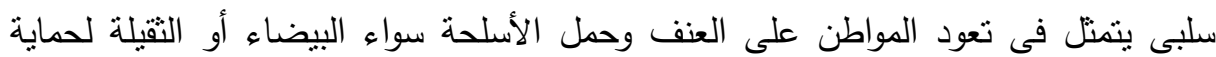

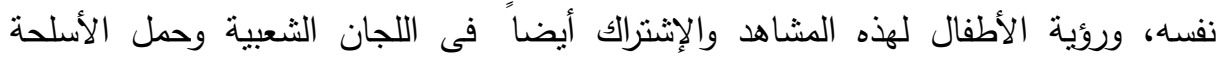

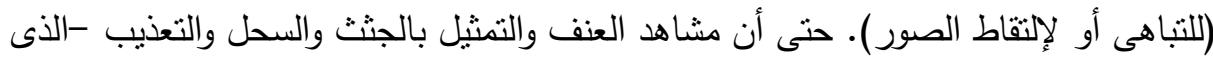

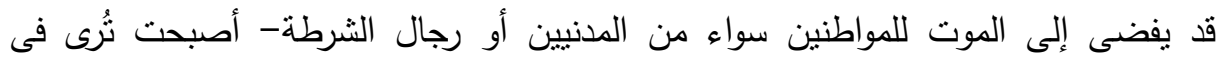

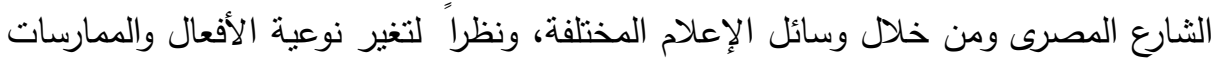

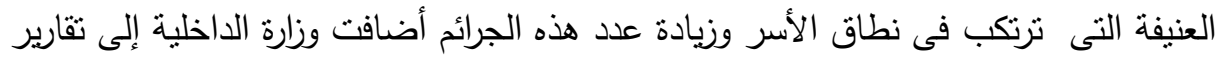
الأمن العام جزء خاص بالجرائم المستحدثة ومنها جرائم العنف الأسرى. لُصن

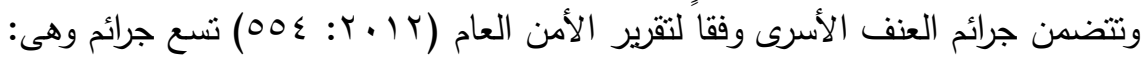

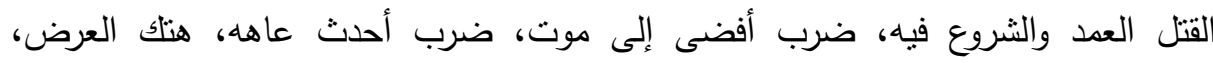
الإغتصاب، السرقة بالإكراه والثروع فيها، الحريق العدد، الخطف والتوقيع على مستتد بالقوه.

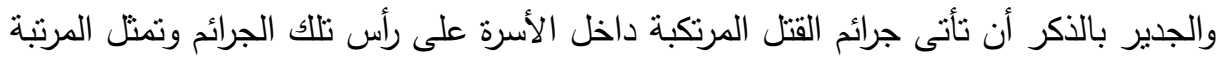

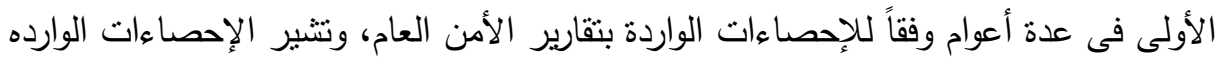

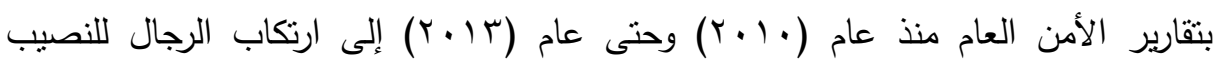

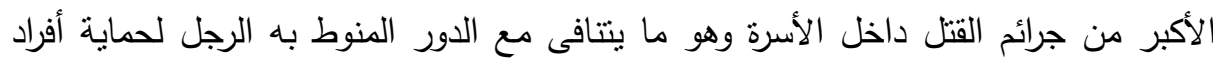

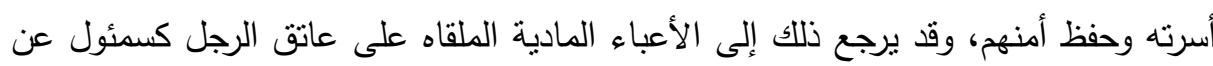

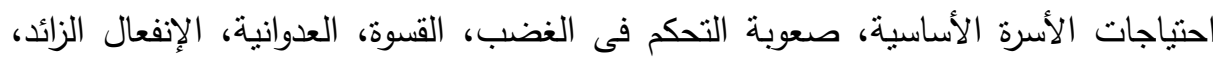
الإعتماد على المواد المخدرة بالإضافة إلى البيئة المحيطة به وما تتضمنه من عوامل ثقافية ونفسية واجتماعية قد تكون باعثه له لإرتكاب العنف التتفيذى تجاه أفراد أسرته.لذا تعنى الدراسة الحالية بالبحث فى الأسباب التى تؤدى بالرجال إلى ارتكاب فعل القتل العدد تجاه أحد أفراد أسرهم من وجهة نظر هؤلاء الرجال سواء المتهمون بارتكاب تلأك الجرائم أوالمحكوم عليهم 


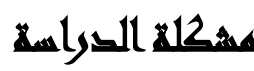

لا نكاد نظلو وسائل الإعلام سواء الدقروء، المسموع أو المرئى من تقارير لرصد جرائم

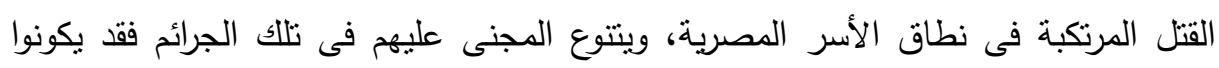

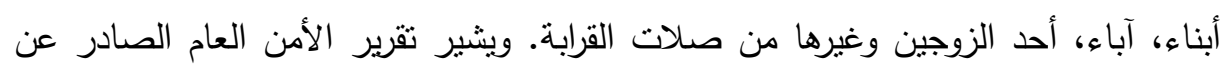

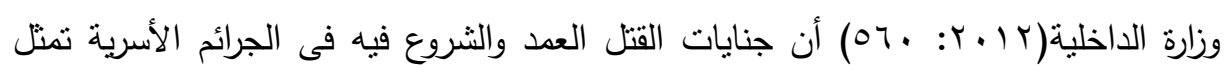

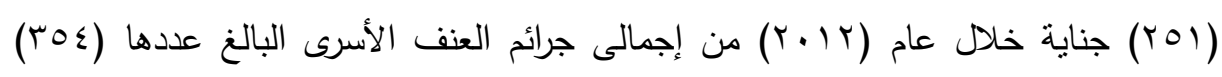

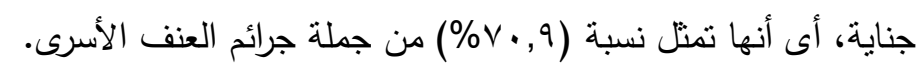

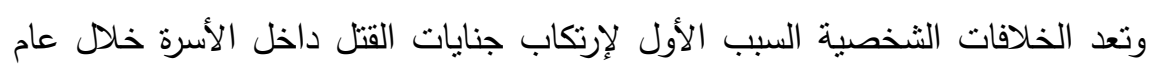

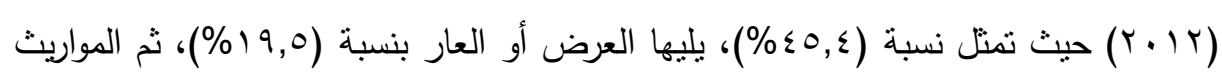

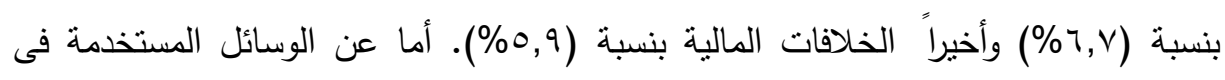

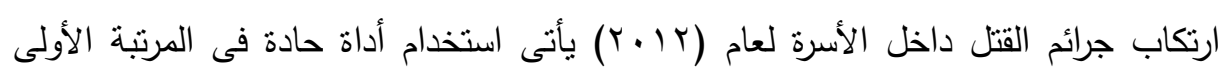

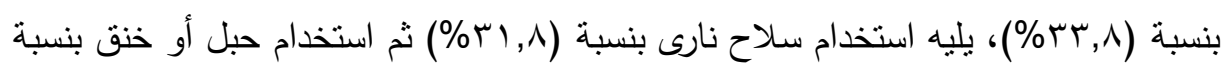

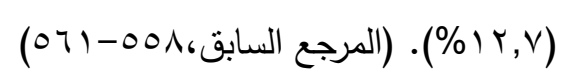

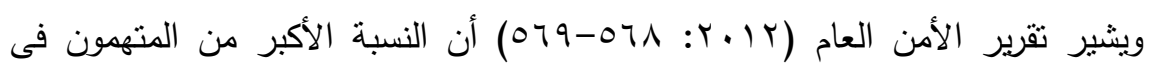

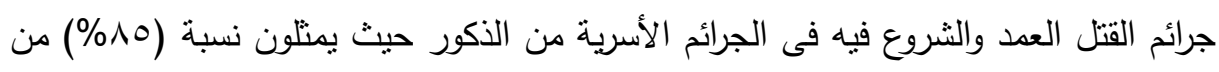

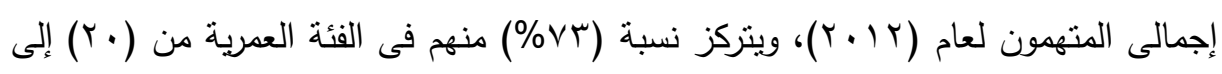

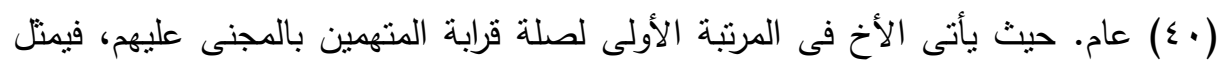

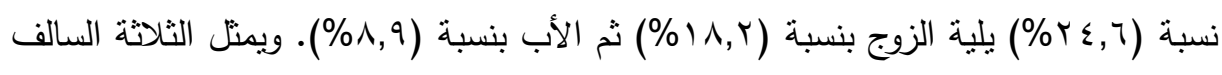

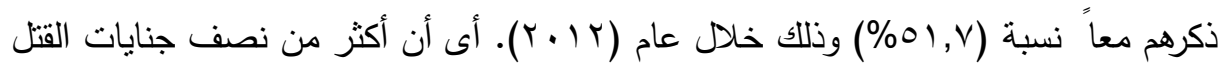

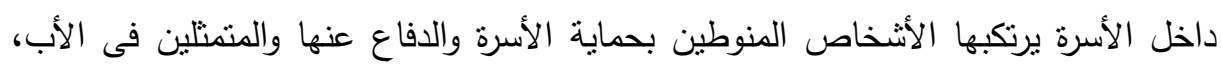

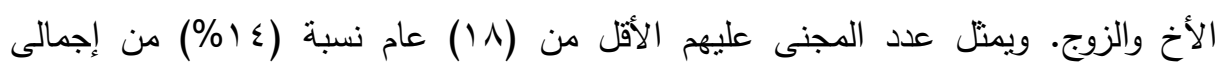

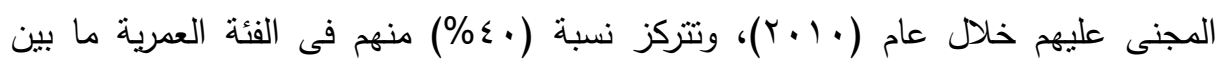
. 
توضح الإحصاءات السالف عرضها حجم جرائم القتل المرتكبة داخل الأسرة المصرية وهو ما يتتافى تماماً مع الدور الأساسى المنوطة به الأسرة من تربية الأبناء ورعاية أفرادها

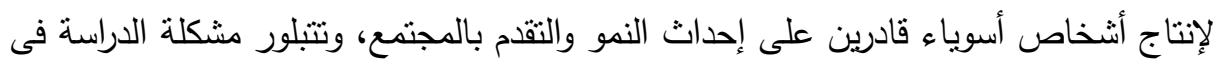

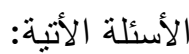

\section{أسئلا الهمبه}

• ما مدى إعتبار المتغيرات الإجتماعية المتمتلة فى (السن، المهنة، المستوى التعليمى،

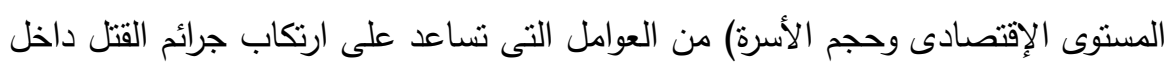

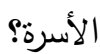

• ما مدى إعتبار المتغيرات النفسية المتمثلة فى ( الإدمان، اضطراب القلق العام) من العوامل التى تساعد على ارتكاب جرائم القتل داخل الأسرة؟ • ما الخصائص الديموجرافية للرجال مرتكبى جرائم القتل داخل الأسرة؟

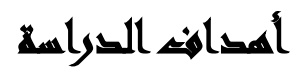

تهذف هذه الدراسة إلى التحقق مما يلى: • تحديد المتغيرات الإجتماعية المرتبطة بالرجال مرتكبى جرائم القتل داخل الأسرة المصرية. • • تحديد المتغيرات النفسية المرتبطة بالرجال مرتكبى جرائم القتل داخل الأسرة المصرية. • تحديد الخصائص الديموجرافية للرجال مرتكبى جرائم القتل داخل الأسرة.

\section{هروض السواسما}

تعتمد الاراسة الحالية على عدد من الفروض تتمثل فى الآتى:

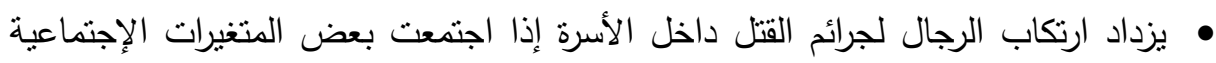

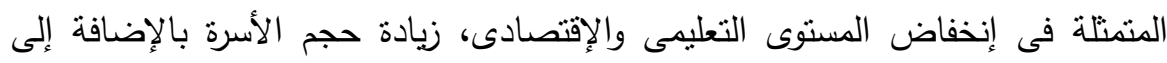
وجودهم فى المرحلة العمرية ما بين العشرون والأربعون عاماً . 
توجد فروق دالة إحصائياً بين منوسطات درجات عينة الدراسة من الرجال مرتكبى جرائم

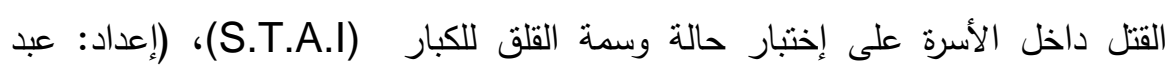

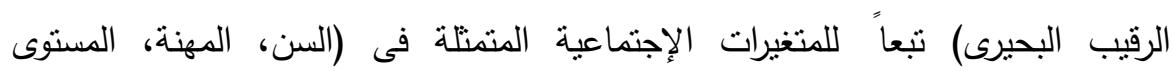

$$
\text { التعليمى، المستوى الإقتصادى، حجم الأسرة). }
$$

توجد علاقة إرتباطية دالة بين الإدمان وإرتكاب الرجال لجرائم القتل داخل الأسرة.

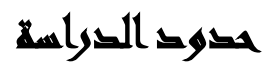

تتحدد هذه الاراسة بعدد من الحدود وهى:

الحدود المكانية: طبقت الدراسة الميدانية على ليمان طره للرجال، وهو ما تم تحديده من من

قبل إدارة العلاقات العامة بقطاع مصلحة السجون.

الحدود الزماتية: أجريت الدراسة الميدانية خلال اسبوع بدأ يوم السبت الموافق

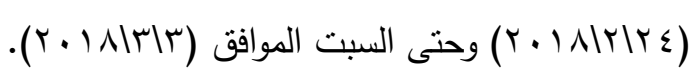

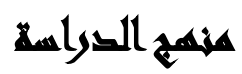

اتبع الباحثون فى الدراسة الحالية المنهج الوصفى الارتباطى المقارن لأنه يهنم بدراسة

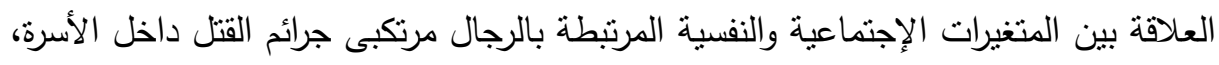

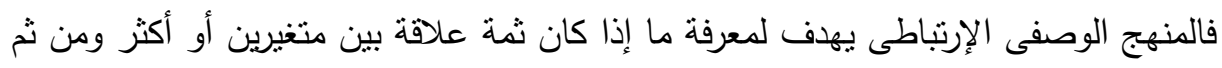
إظهار مقدارها.

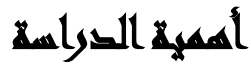

نظراً للتغير الملحوظ فى نوعية الجرائم المرتكبة داخل الأسرة المصرية وزيادة نسب

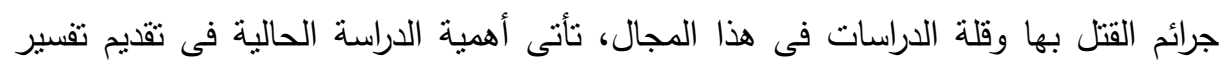
للأسباب التى يمكن أن تدفع الرجال لقتل أفراد أسرهم وتحديد أهم المتغيرات الإجتماعية التهية والنفسية وثيقة الصلة بتلك الجريمة بالإضافة إلى تحديد بعض السمات المشتركة بين هؤلاء

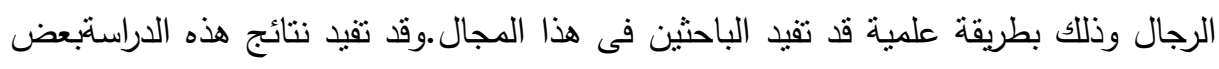

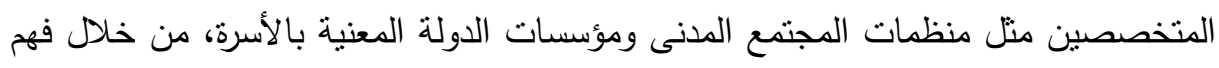

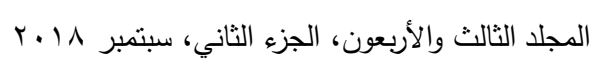


أفضل لطبيعة الظروف التى تمر بها الأسر التى ترتكب فيها جرائم القتل وتحديد خصائص مرتكبيها استتاداً على أسس ونتائج علمية.

\section{مهذامهير التراسما}

تتحدد المفاهيم الأساسية للاراسة الحالية فيما يلى: التعريف الإجرائى للمتغيرات الاجتماعية: يقصد الباحثون بالمتغيرات الإجتماعية فى لئه هذه الدراسة متغيرات السن، المهنة، المستوى التعليمى، المستوى الإقتصادى وحجم الأسرة

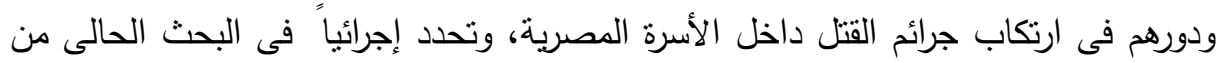
خلال الدرجات التى يحصل عليها أفراد عينة البحث على استمارة البيانات الأولية للرجال مرتكبى جرائم القتل داخل الأسرة المستخدمة فى الدراسة. التعريف الإجرائى للمتغيرات النفسية: يقصد الباحثون بالمتغيرات النفسية فى هذه الدراسة الإدمان، اضطراب القلق العام وتحدد إجرائياً فى البحث الحالى من خلال الدرجات التى يحصل عليها أفراد العينة على المقياس المستخدم فى الدراسة وهو: إختبار حالة وسمة الإنة القلق للكبار (S.T.A.I) (إعداد عبد الرقيب البحيرى).

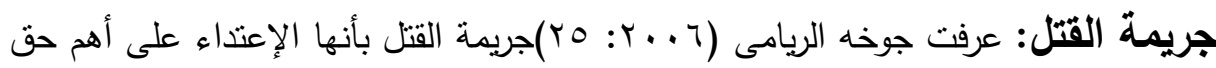
من حقوق الإنسان وهو الحق فى الحياة، ويتحقق ذلك بطريقتين: إما قيام الجانى بإزهاق روح إنسان آخر على قبد الحياة أو أن ينهى الإنسان حياتة بنفسه (كما فى الإنتحار ).

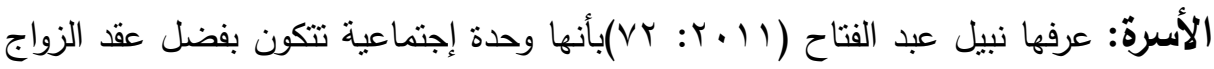
بين الرجل والمرأة من أجل تحقيق المودة والرحمة بينهما وتسيير معيشتهما المشتركة وإنجاب الأولاد وتربيتهم. 


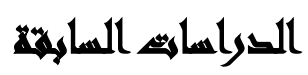

• أجرت إيمان شريف قائد( ( . . P) دراسة بهدف إلقاء الضوء على الصور والأتكال

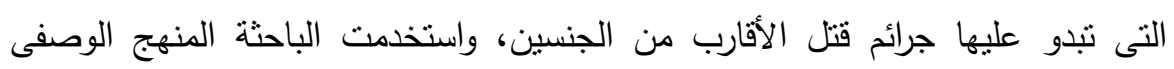

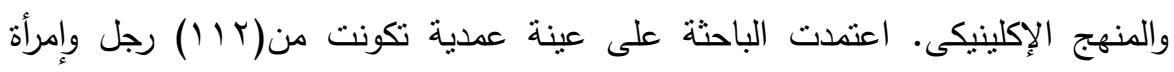

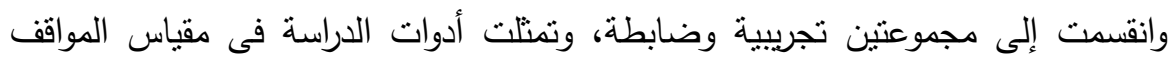

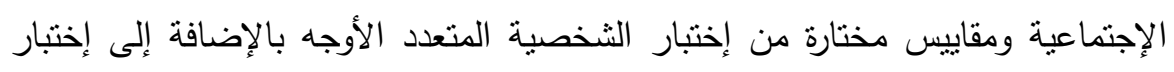

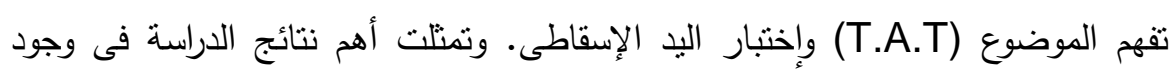

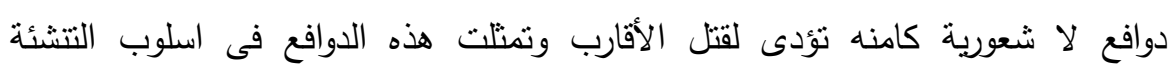

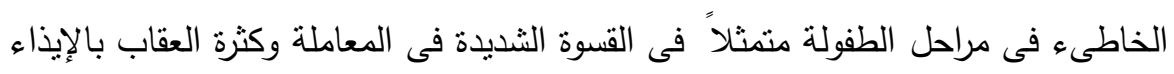
البنىى، وكثرة الخلافات والهشاكل الأسرية والتفكلك الأسرى. • وهلفت دراسة جون، مارك (Jon, Mark, 2010) إلى فحص بيانات السجناء

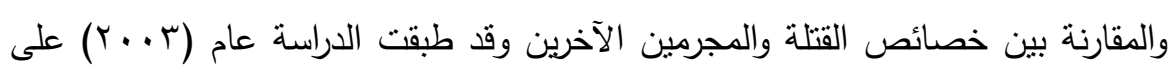

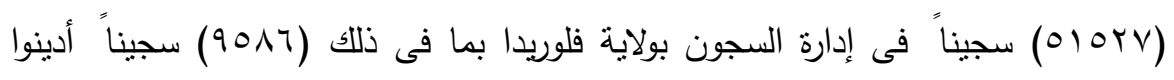

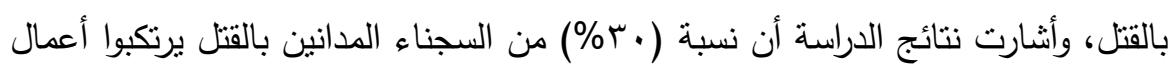

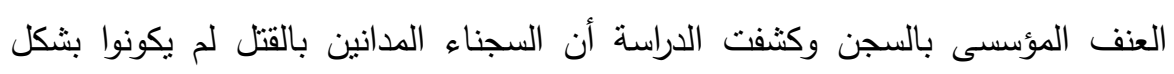

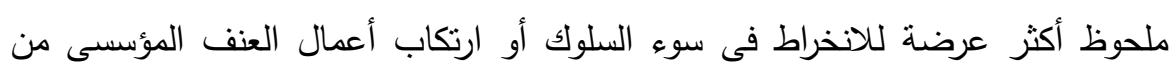
السجناء الذنين يقضون عقوبات لجرائم أخرى.

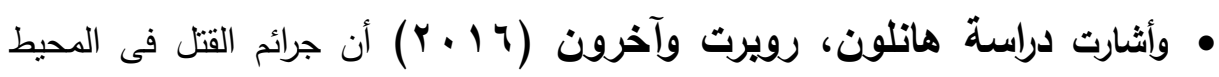

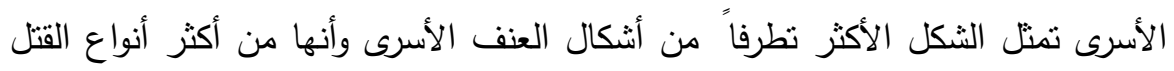

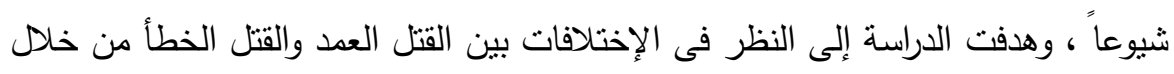

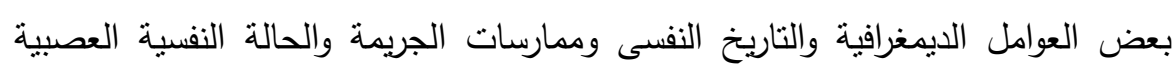

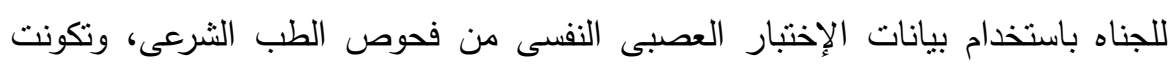

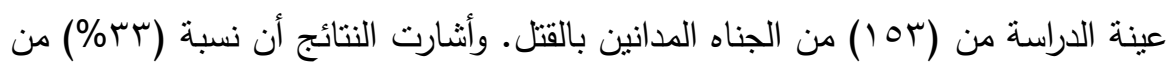

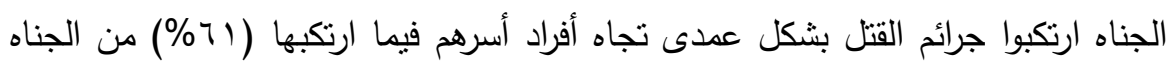

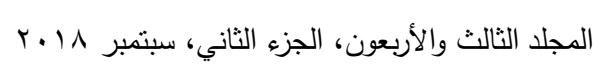


عن طريق الخطأ، وبينت النتائج أن الجناه مرتكبى جرائم القتل العمد أكثر عرضة للإضطرابات النفسية الصريحة وأقل عرضة لنتخيص اضطراب الثخصية المعادية للمجتمع أو أن يكون لهم إدانات جنائية سابقة.

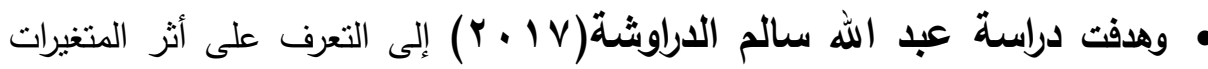
الإجتماعية على إرتكاب جريمة القتل فى المجتمع الأردنى من وجهة نظر طلبة الجامعات الأردنية،واعتمد الباحث على منهج المسح الإجتماعى واستخدم العينة العشوائية البسيطة وتكونت من (Tr؟) مفرده من طلبة الجامعات الأردنية واستخدم الباحث الإستنيان كأداة

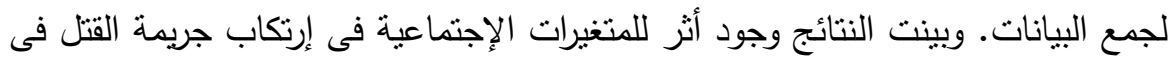

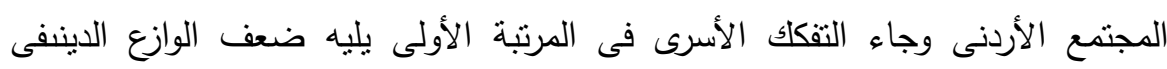
المرنبة الثانيةوفى المرنبة الثالثة ضعف وهاء الفكائل الانئل الضبط الإجتماعى.

\section{الإطال اللنظاره}

مفهوم جريمة القتل: أشار هشام عبد الحميد (ع ا.ب: 10) أن القتل من المنظور

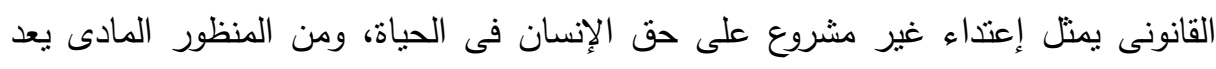

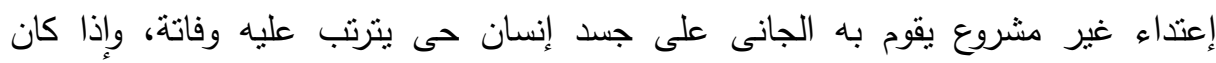
الإعتداء وقت إرتكاب الجريمة قد وقع على ميت فلا تقوم جريمة القتل فالحماية الجنائية

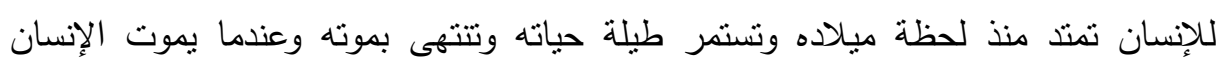

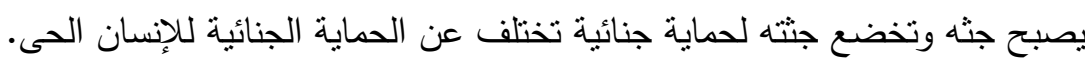

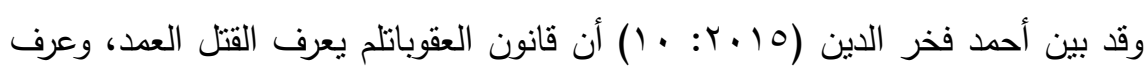

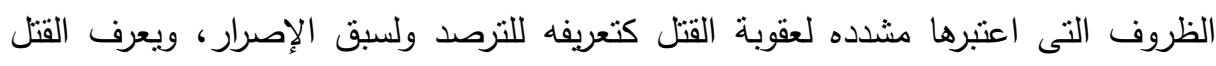
العدد بأنه: إزهاق روح إنسان بفعل إنسان آخر تعدداً . وتتنهى الحياة حين يلفظ الإنسان نفسه

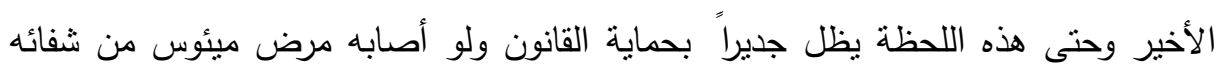

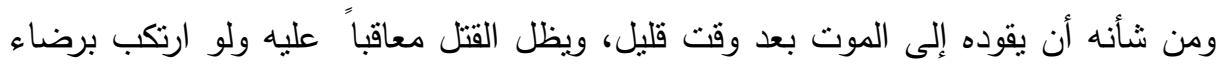

$$
\text { المجنى عليه بل لو ارتكب بناء" على طلبه. }
$$


وتعرف جريمة القتل فى الدراسة الحالية بأنها: فعل يرتكبه شخص أو أكثر تجاه إنسان

حى بقصد إنهاء حياته، ويترتب على هذا الفعل إنهاء حياته وإزهاق روحهـ.

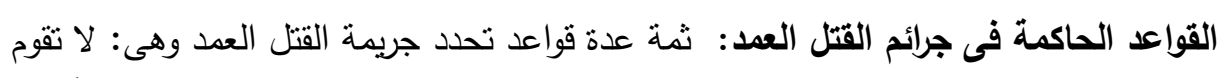

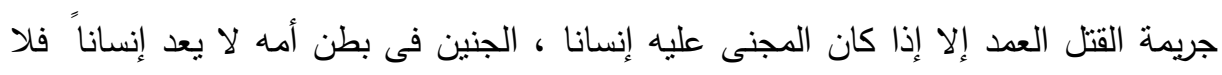

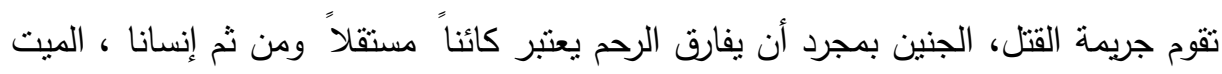

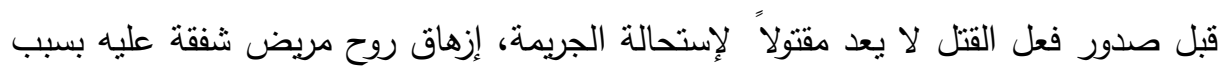

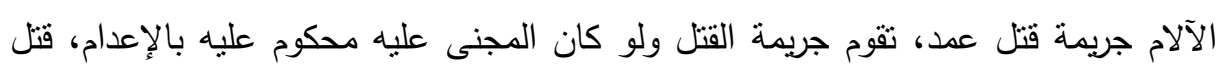

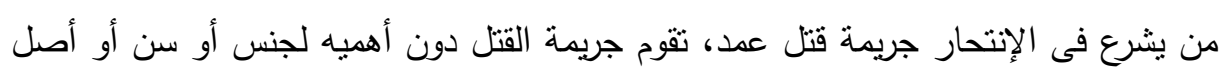

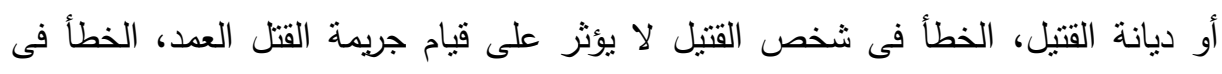

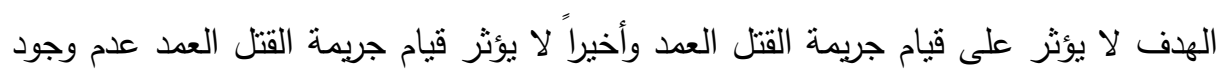

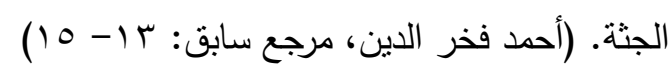

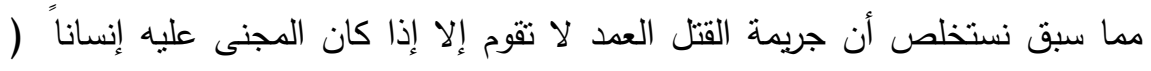

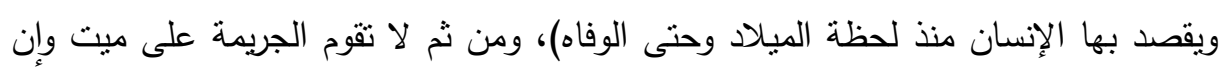

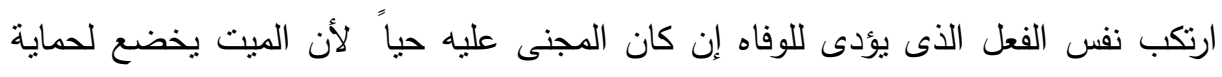

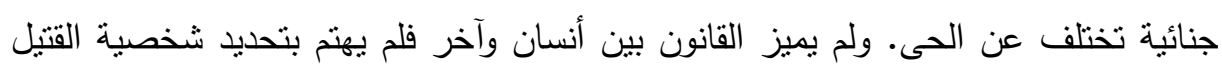

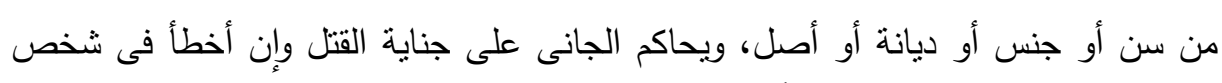

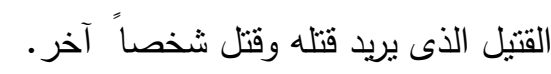

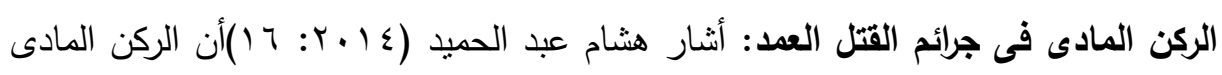
فى جرائم القتل العديتمثل فى سلوك إجرامى، نتيجة وعلاقة سبيية تربط بين السلوك والنتيجة.

\section{النظريات المفسرة للسلوك الإجرامى:}

ا ـ نظرية التحليل النفسى: يرى فرويد أنه ثمة مجموعنين أساسيتين من الغرائز وهى (غرائز

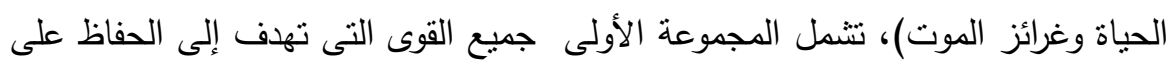
العلميات الحياتية الحيوية وبقاء النوع وتكاثره واعتبر فرويد أن الغرائز الجنسية أكثر غرائز

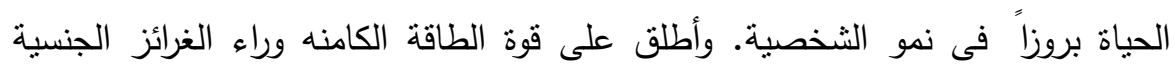
مصطلح اللبيدو Libido وهو مشتق من كلمة لاتينية بمعنى الرغبة، ويقصد بالطاقة

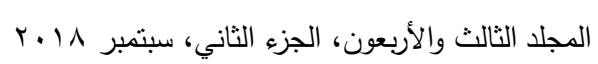


اللبيدية طاقة غرائز الحياة بصفة عامة والطاقة النفسية التى تبحث عن إثباع من خلال الأنشطة الجنسية بصفة خاصة. أما غرائز الموت فقد اعتبر أنها وراء مظاهر القوة

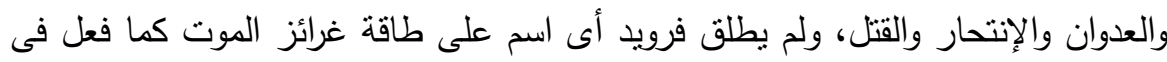

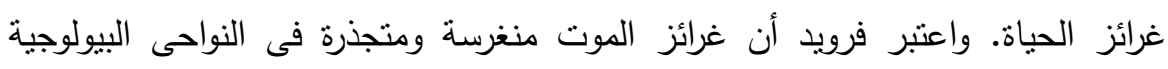

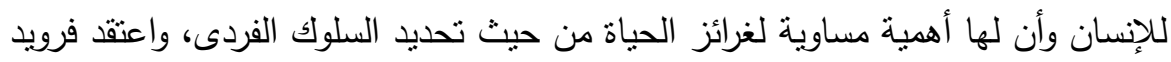
أن لاى كل شخص رغبة داخلية لا شعورية فى الموت وأن جميع الكائنات الحية مضطرة

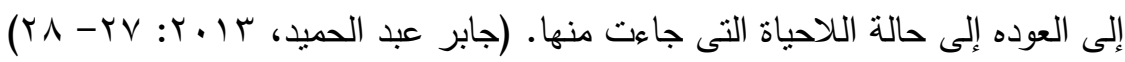

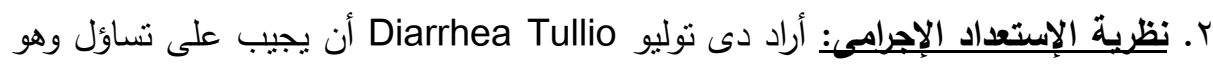

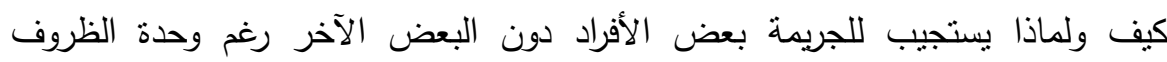

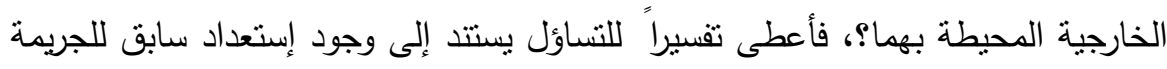
لاى بعض الأفراد نتيجة تكوين خاص للشخصية الفردية واتسامها بصفات عضوية،

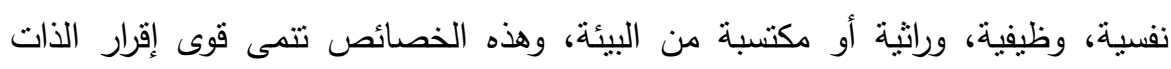

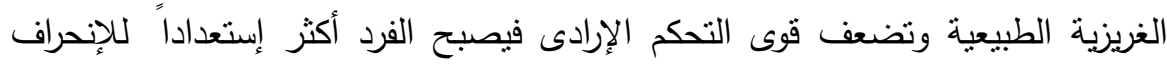

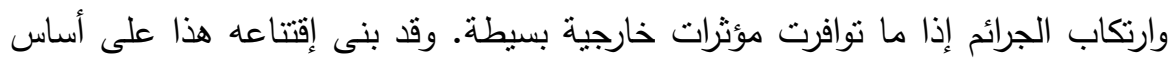

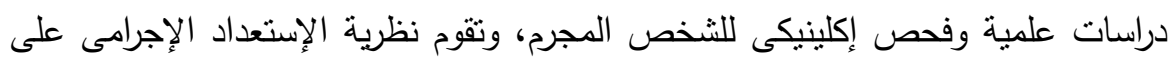

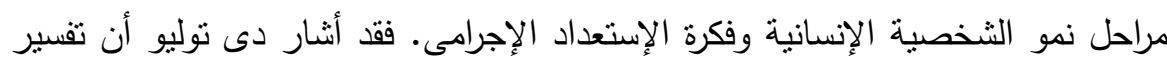

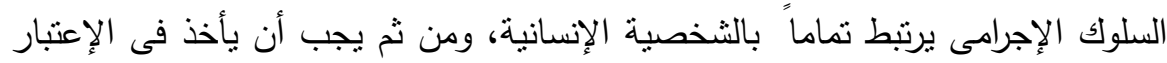
كل ما يرتبط بالعمليات الطبيعية (البيولوجية، النفسية والوظيفية) للفرد والتى تتمو تدريجياً

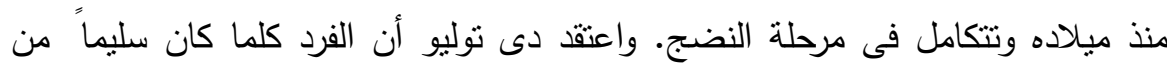
الوجهه النفسية أمكنه السيطرة على الدوافع العدوانية وتوجيه سلوكه بما يتفق مع سائر القيم

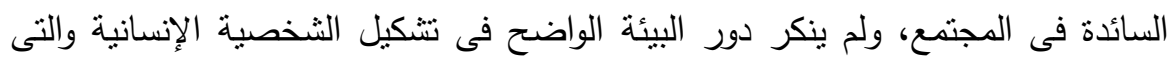

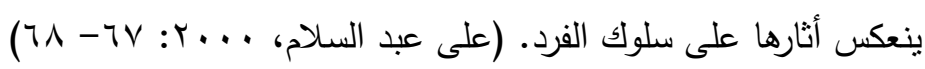


r. النظرية التكاملية: أنشار جعفر عبد الأمير أن أصحاب هذه النظرية يفسرون الجنوح

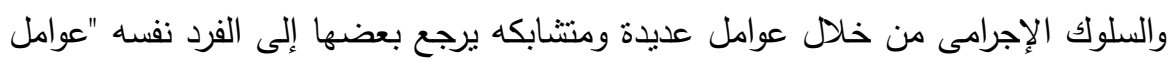

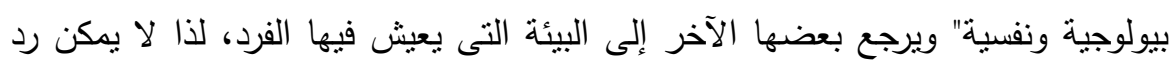

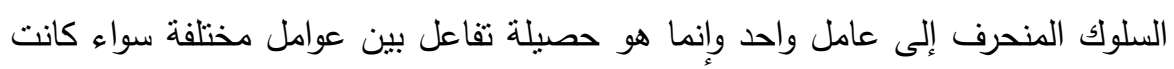
عضوية، نفسية، وراثية، بيئية أو إجتماعية. فلا يمكن النظر إلى الفرد بمعزل عند عن البيئة

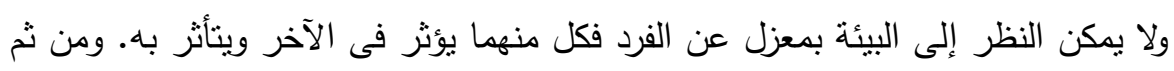

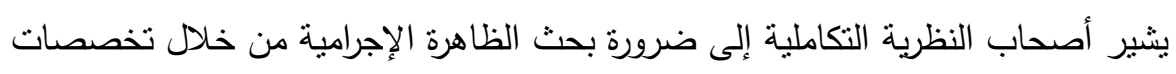

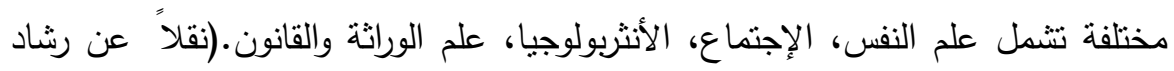

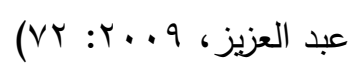

تعقيب على النظريات المفسرة للسلوك الإجرامى: تعد نظرية التحليل النفسى من النظريات

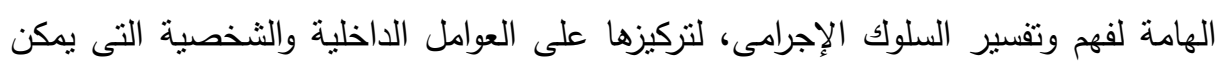

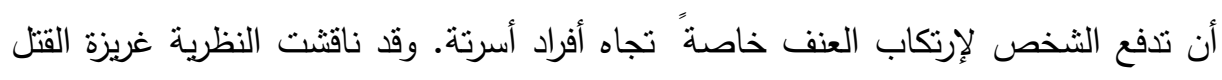

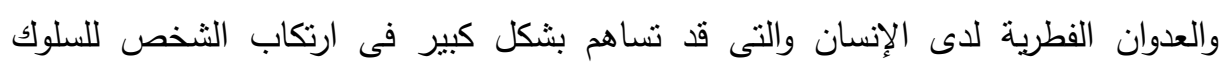

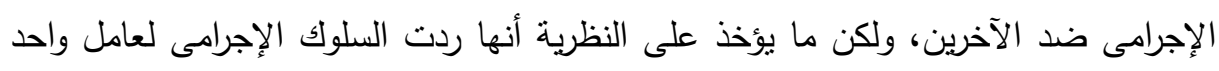

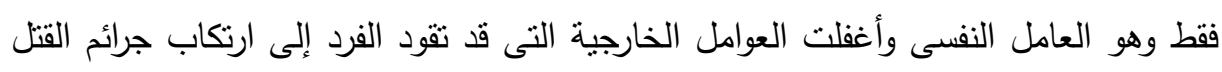

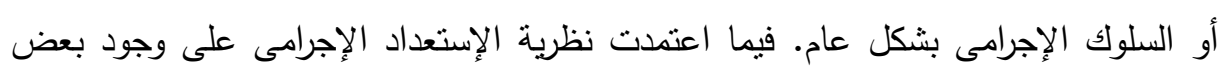

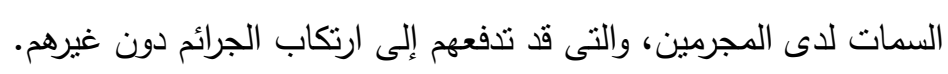

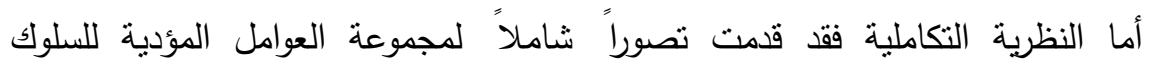

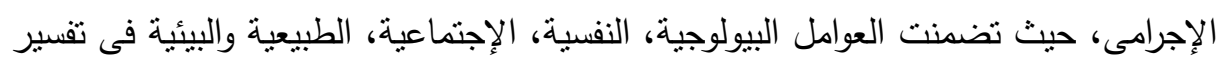

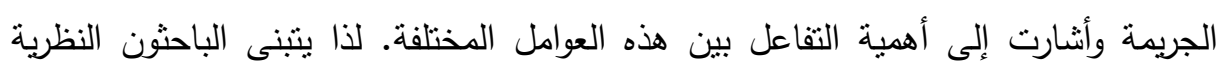

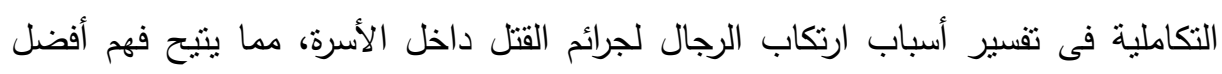
للعوامل المختلفة التى يمكن أن ثقود الرجال إلى ارتكاب هذه الجير الجريمة. 


\section{إجراءايه التواسمة}

عينة الاراسة: اقتصرت عينة الدراسة على عينة عشوائية من الرجال مرنكبى جرائم القتل داخل الأسرة والمتواجدين بليمان طره وتكونت من ( (10) مفرده، وتم إجراء دراسة حالة لثمانية رجال منهم وفيما يلى سيتم توضيح خصائص العينة وشروط اختيارها. أ. شروط إختيار العينة: تم تحديد شرط واحد لإختيار العينة وهو أن يكونوا من الرجال مرتكبى جرائم القتل العدد تجاه أفراد أسرهم (سواء كانوا متهمين أو محكوم عليهم جنائياً فى هذه الجرائم).

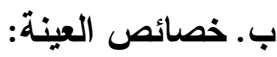

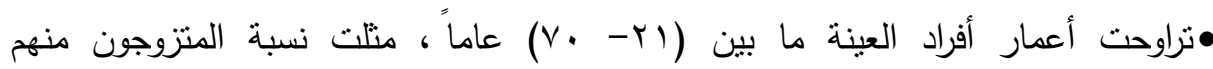

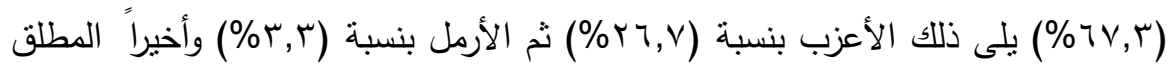

$$
\text { بنسبة (\% r, ) }
$$

•النسبة الأكبر منهم حاصلون على تعليم منوسطبنسبة (r, آr\%) يلى ذلك الأميون بنسبة

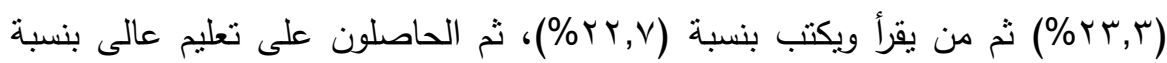

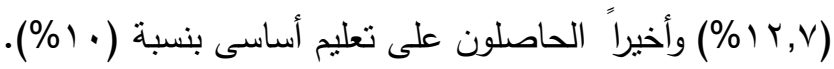

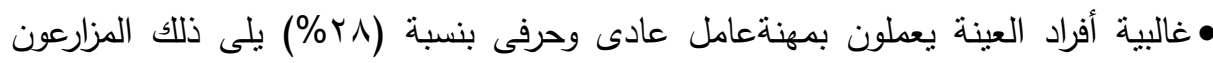

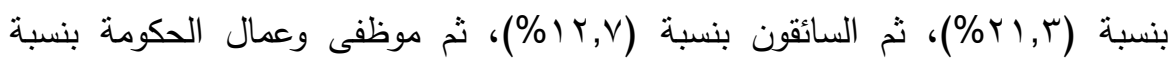

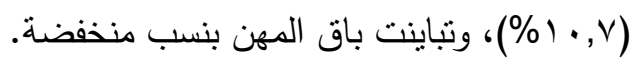

أدوات الدراسة: طبقت الدراسة الميدانية على ليمان طره للرجال خلال اسبوع بدأ يوم السبت باتب

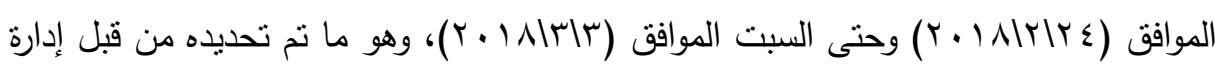
العلاقات العامة بقطاع مصلحة السجون.وتتمنل أدوات الدراسة الحالية فيما يلى: (إختبار حالة مهن وسمة القلق للكبار (S.T.A.I)،"إعداد عبد الرقيب البحيرى"، استمارة البيانات الأولية "إعداد إلئه الباحثون"، إستمارة دراسة الحالة "إعداد الباحثون")، وفيما يلى وصف لاستمارة دراسة الحالة. 
( ) الوصف العام لإستمارة دراسة الحالة: تكونت الإستمارقمن (·r) عبارة اثتملت على

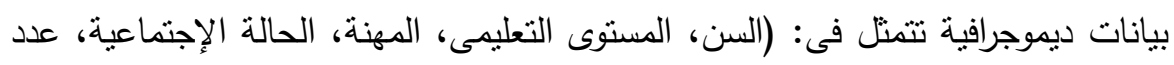

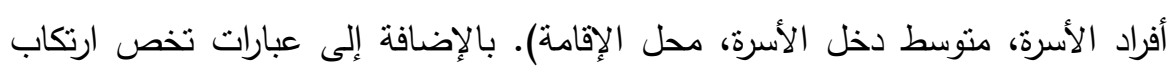

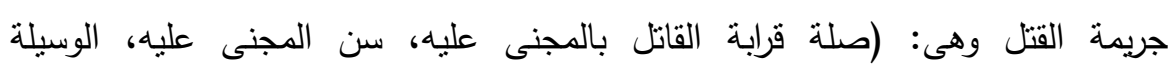
المستخدمه فى القتل، عدد المرات التى حكم على القاتل فيها بالسجن من قبل -المعرفة إذا

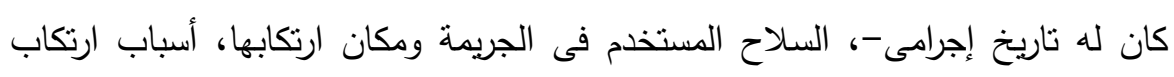
جريمة القتل وطريقة ارتكابها وطريقة اكتثاف الجريمة بالإضافة إلى طبيعة علاقة القاتل بالمجنى عليه قبل ارتكاب جريمةالقتل)، واختص الجزء الأخير بعبارات تخص التدخين

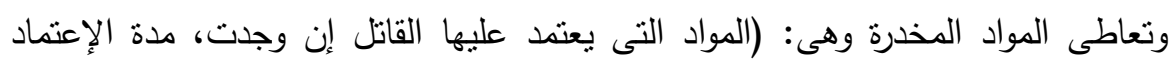

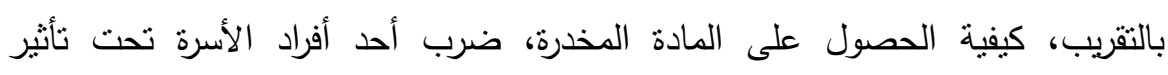

r بات استمارة دراسة الحالة: للتحقق من ثبات الاستمارة استخدم الباحثون معادلة ألفا كرونباخ وقد بلغت قيمة معامل الثبات (1 الT, · )، وتتثير هذه القيمة إلى صلاحية استمارة دراسة الحالة وإمكانية الاعتماد على نتائجها والوثوق بها حيث كانت أكبر من (0, (•) ).

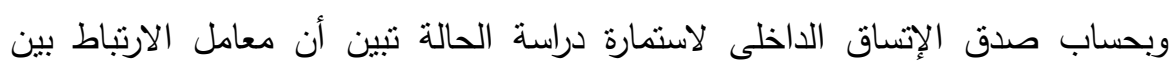

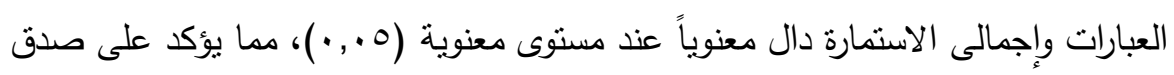
الاتساق الداخلى لعبارات استمارة دراسة الحالة. r) الأساليب الإحصائية المستخدمه فى الاراسة: استخدم الباحثون الأساليب الإحصائية

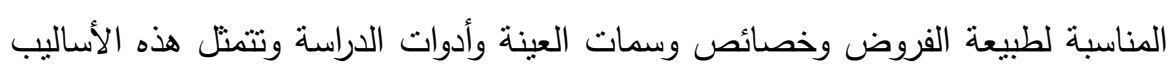
فيما يلى: (معامل ألفا كرونباخ، معامل ارتباط بيرسون، معامل ارتباط سبيرمان، إختبار التباين المتعدد). 


\section{نمأئج التصاسة}

1 - عرض النتائج الخاصة بالفرض الأول والذى ينص على: " يزداد ارتكاب الرجال لجرائم

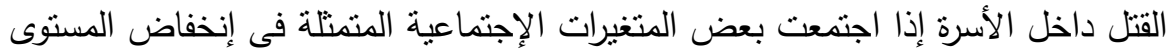
التعليمى والإقتصادى، زيادة حجم الأسرة بالإضافة إلى وجودهم فى المرحلة العمرية ما بين

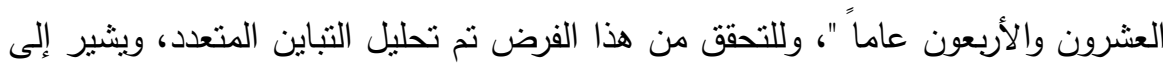

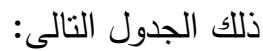

\begin{tabular}{|c|c|c|c|c|c|c|}
\hline ||لالالة| & (ختبارة & المتوبعات & الدرية & |المربعات & المتغيرات & مصدر التباين \\
\hline$\cdot, Y$ & $1, \vee 11 \varepsilon$ & $Y, Y \cdot V$ & 1 & $Y, Y \cdot V$ & السن & \multirow{4}{*}{ النموذج المصحح } \\
\hline$\cdot, \cdot V$ & $r, \varepsilon \leqslant \Lambda$ & $7, V \cdot V$ & $T$ & $7, V \cdot V$ & التعليم & \\
\hline$\cdot, 0$ & $\cdot, 199$ & $\cdot, 1 \leq \mu$ & 1 & $\cdot, 1 \leq \mu$ & عددآفرادا لاسرة & \\
\hline$\cdot, r$ & 1,170 & 1,991 & 1 & 1,991 & متوسطدخلالاسرة & \\
\hline$\cdot, \ldots$ & $\leqslant 0 \wedge, 9 \cdot 0$ & $O V \varepsilon, Y \cdot V$ & $T$ & $\mid O V \varepsilon, Y \cdot V$ & السن & \multirow{4}{*}{ الثنابت } \\
\hline$\cdot, \ldots$ & $|\vee \Gamma, \varepsilon \Sigma|$ & TrV,rVT & $T$ & rrv,rvr| & التعليم & \\
\hline$\cdot, \ldots$ & $r \circ \Lambda, 1 \leqslant \Lambda$ & IYA,Tr & 1 & $\mid T \Lambda, r Y$ & عددآفرادالاسرة & \\
\hline$\cdot, \ldots$ & $\mid 101, \cdot T_{1}$ & Yq0,乏०V & $T$ & Y $90, \leqslant 0 V$ & متوسطلخلالاسرة & \\
\hline$\cdot, r$ & $1, \vee \backslash \varepsilon$ & $Y, Y \cdot V$ & $T$ & $Y, Y \cdot V$ & السن & \multirow{4}{*}{ القتلن داخل الأسرة لجرائ } \\
\hline$\cdot, \cdot \mathrm{V}$ & $r, \varepsilon \leqslant \wedge$ & $7, V \cdot V$ & $T$ & $T, V \cdot V$ & التعليم & \\
\hline., 0 & $\cdot, \Gamma 99$ & $\cdot, 1 \leqslant r$ & 1 & $\cdot, 1 \leqslant r$ & عددآفرادالاسرة & \\
\hline$\cdot, r$ & $1, .70$ & 1,991 & $T$ & 1,991 & متوسطلخلالاسرة & \\
\hline & & $1, Y 01$ & $1 \leqslant \Lambda$ & $\mid \wedge 0,1 \wedge \overline{\mid}$ & السن & \multirow{4}{*}{ الخطأ } \\
\hline & & $1,9 \leq 0$ & $1 \leqslant \Lambda$ & $r \wedge \vee, \wedge \wedge V$ & التعليم & \\
\hline & &.,$\mu 0 \Lambda$ & $1 \leqslant \lambda$ & $O r, \cdot r$ & عددأفرادا الاسرة & \\
\hline & & $1, \wedge \vee$ & $1 \leq \Lambda$ & $Y \vee \neg, \vee \cdot Y$ & متوسطلخلالاسرة & \\
\hline & & & 10. & $1 \mathrm{VIV}$ & السن & \multirow{5}{*}{ الإجمالي } \\
\hline & & & 10. & $104 \pi$ & التعليم & \\
\hline & & & 10. & 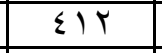 & عددأفرادالأسرة & \\
\hline & & & 10. & ITVY & متوسطدخلالاسرة & \\
\hline & & & $1 \leq 9$ & rVA,79M & متوسطدخلالاسرة & \\
\hline
\end{tabular}

أوضح الجدول السابق عدم وجود نأثثر للمتغيرات الإجتماعية المنمنلة فى (السن، المهنة، المستوى التعليمى، المستوى الاقتصادى، حجم الأسرة) على ارتكاب الرجال لجرائم

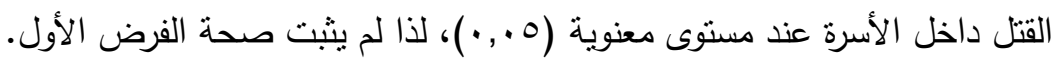


r - عرض النتائج الخاصة بالفرض الثانى والذى ينص على:"توجد فروق دالة إحصائياً بين

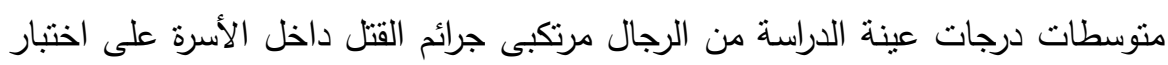

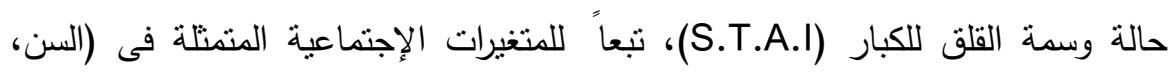

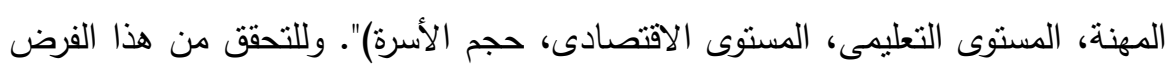

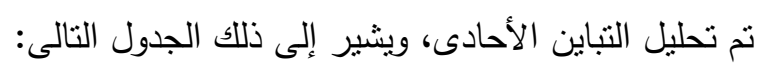

\begin{tabular}{|c|c|c|c|c|c|c|}
\hline المعنوية & 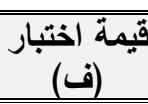 & المتوبعات & الحرجية & المريعات & & المتغيرات \\
\hline \multirow{3}{*}{$\cdot, 0$} & \multirow{3}{*}{$\cdot, \wedge \leq 0$} & $\varepsilon \wedge, \vee 9 \vee$ & $\varepsilon$ & 190,119 & بين الدجموعات & \multirow{3}{*}{ السن } \\
\hline & & OV,VOY & $1 \leqslant 0$ & $\wedge r \vee r, q \wedge \varepsilon$ & داخل المجموعات & \\
\hline & & & $1 \leq 9$ & $1079,1 \vee r$ & الإجمالى & \\
\hline \multirow{3}{*}{$\cdot, r$} & \multirow{3}{*}{ 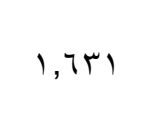 } & $9 Y, Y 70$ & $\varepsilon$ & $r 79, .7$ & بين المجموعات & \multirow{3}{*}{ التعليمية } \\
\hline & & 07,004 & $1 \leq 0$ & $\Delta r \ldots, 11 r$ & داخل المجموعات & \\
\hline & & & $1 \leq 9$ & $1079,1 \vee r$ & الإجمالى & \\
\hline \multirow{3}{*}{$\cdot, r$} & \multirow{3}{*}{$1, r 19$} & $79,91 \pi$ & r & $1 \Gamma q, \wedge Y T$ & ببن الدجموعات & \multirow{3}{*}{ عدد أفراد } \\
\hline & & $O V, r \leqslant Y$ & $1 \leqslant V$ & $\Lambda \leqslant Y q, \Gamma \leqslant V$ & داخل المجموعات & \\
\hline & & & $1 \leq 9$ & $1079,1 \vee r$ & الإجمالى & \\
\hline \multirow{3}{*}{$\cdot, \cdot \varepsilon$} & \multirow{3}{*}{$r, \leqslant T$} & $1 \mu r, \varepsilon \cdot r$ & 0 & $77 \%, .1 \varepsilon$ & بين المجموعات & \multirow{3}{*}{ الاقتصادي } \\
\hline & & $0 \leqslant, \lambda \vee \uparrow$ & $1 \leq \varepsilon$ & $V 9 . r, 109$ & داخل المجموعات & \\
\hline & & & $1 \leqslant 9$ & $1079,1 \vee r$ & الإجمالى & \\
\hline
\end{tabular}

أوضح الجدول السابق وجود فروق ذات دلالة إحصائية عند مستوى معنوية (0. . •) بين

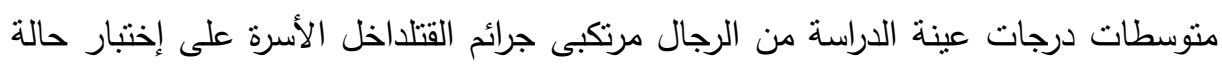

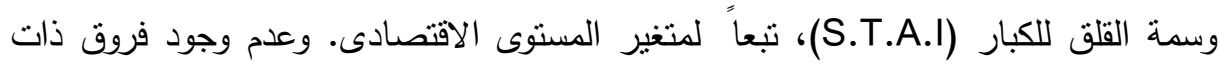
دلالة إحصائية عند مسنوى معنوية (0., •) بين متوسطات درجات عينة الدراسة من الرجال

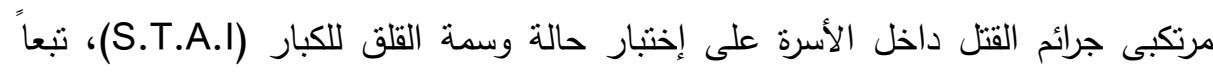

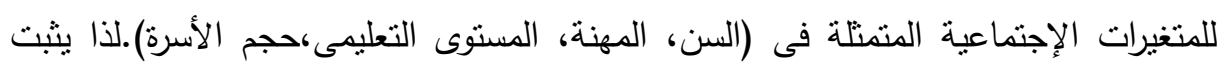

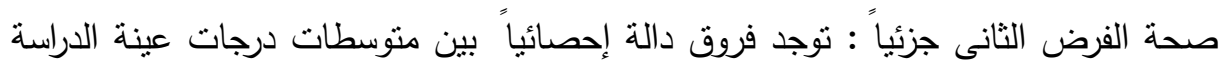

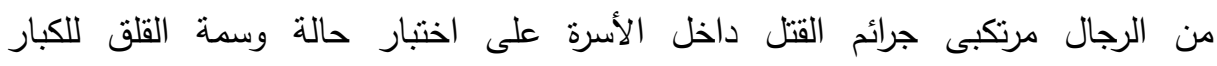

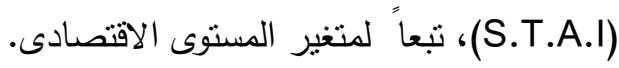


r- عرض النتائج الخاصة بالفرض الثالث والذى ينص على: "توجد علاقة إرتباطية دالة بين

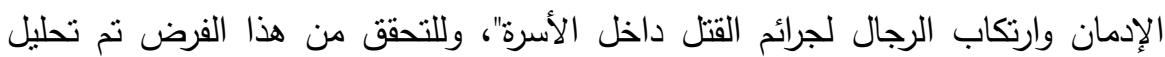

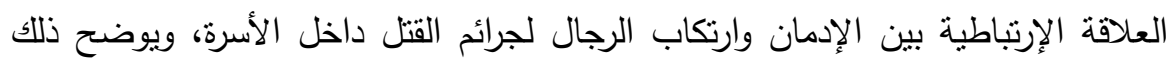

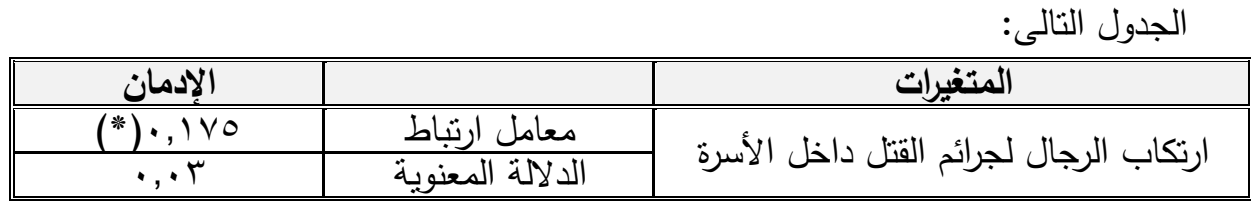

أوضح الجدول السابق وجود علاقة ذات دلالة إحصائية عند مستوى معنوية (0.,.•)

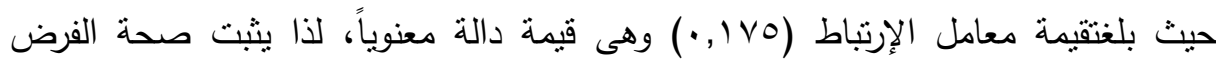
الرابع.

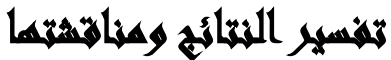

نحاول فى هذا الجزء تفسير ومناقشة نتائج الدراسة وفقا لفروضها، للوقوف على دلالتها النفسية. بالنسبة لنتائج الفرض الأول، فقد أنثارت فى مجملها إلى أن الأسر التى تجتمع فيها

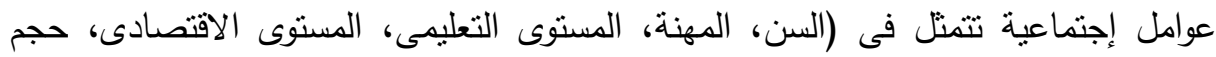
الأسرة) لا يشترط أن برتكب الرجال فيها لجرائم القتل داخل الأسره وهى نتيجة مقبولة فئلة بالنسبة

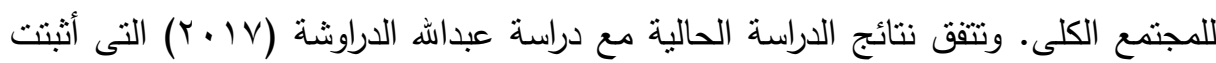
عدم وجود فروق ذات دلالة إحصائية على ارتكاب جريمة القتل فى المجتمع الأردنى تبعاً

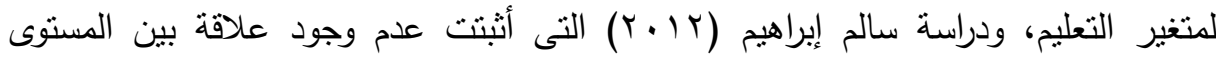

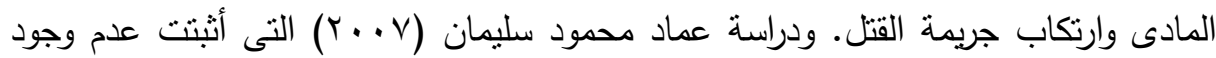
فروق ذات دلالة إحصائية بين الأطفال الذين تعرضوا والذين لم يتعرضوا للعنف الأسرى تبعاً

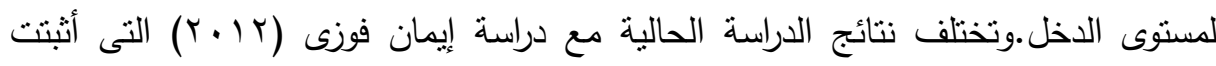
وجود علاقة إرتباطية بين الدخل الثهرى وارتكاب العنف بين الزوجين، ووجود علاقة إرتباطية

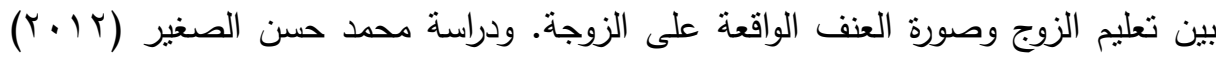

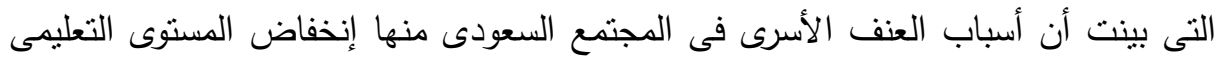




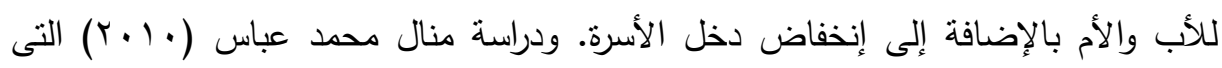

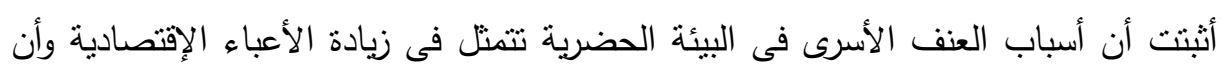

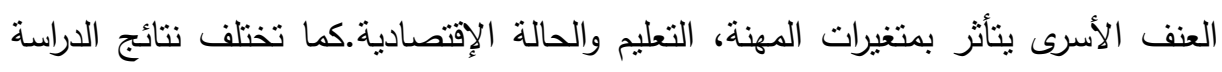

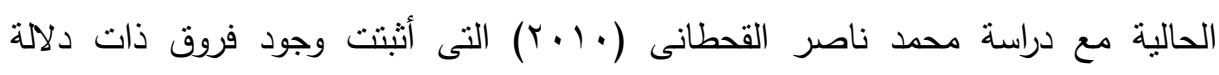

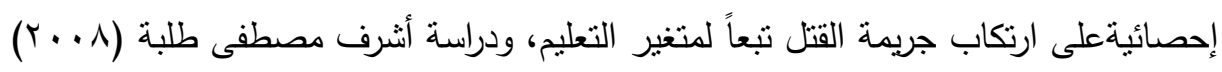

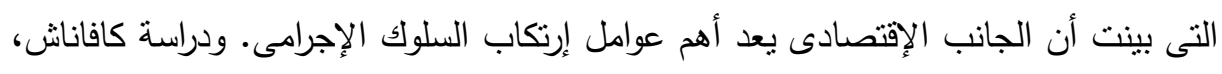

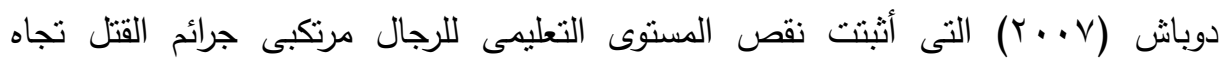

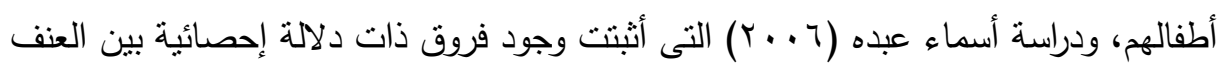

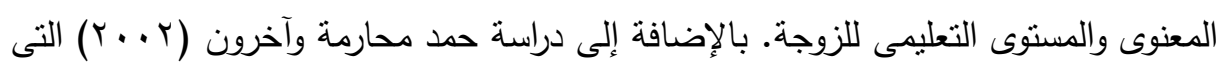

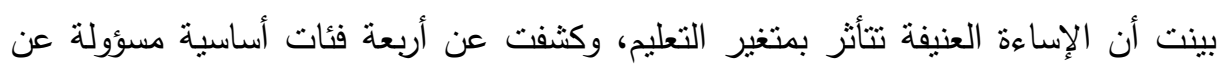

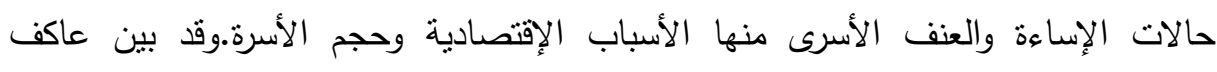

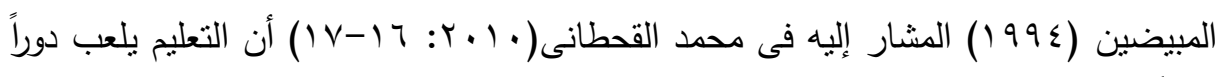
هاماً فى التقليل من إرتكاب جرائم القتل، وأشار أن تعليم وتقافة الفرد تؤدى إلى إخماد الميول

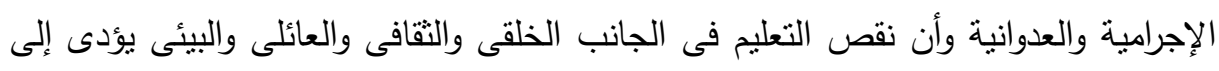

إبراز تللك الميول الإجرامية.ويمكن إرجاع هذه النتيجة لعدة أسباب وعوامل منها: • طبيعة المجتمع المصرى الذى يتسم بالتدين، وقد حرمت الثرائع السماوية قتل النفس.

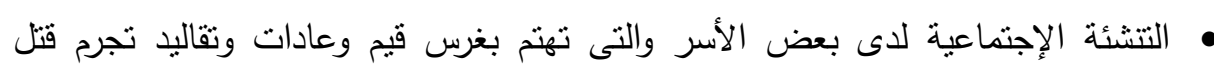

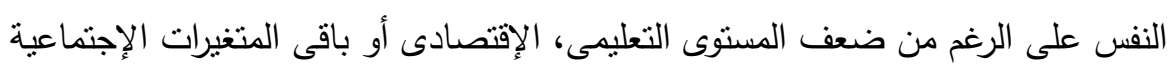

$$
\text { للاراسة الحالية. }
$$

وقد أشارت نتائج الفرض الثانى،إلى ثثوت صحتة جزئياً بوجود فروق دالة إحصائياً بين متوسطات درجات عينة الدراسة على إختبار حالة وسمة القلق للكبار (S.T.A.I) تبعاً

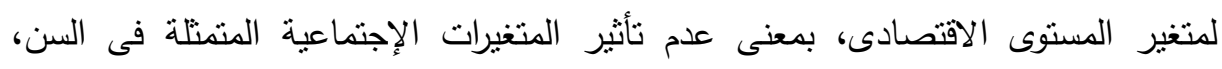

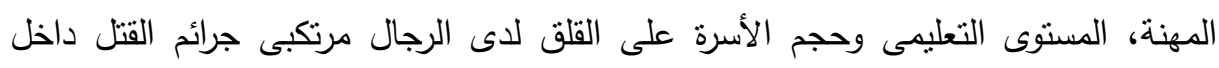

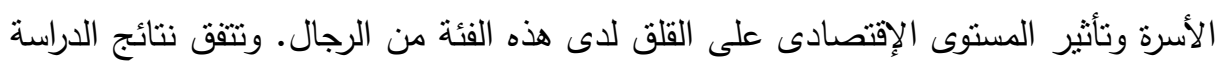

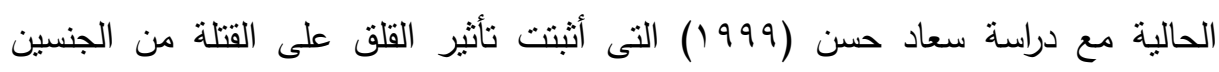

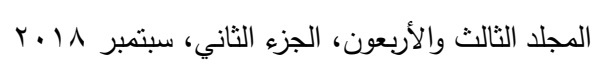


وأثنارت أن القلق الثديد يظهر من التخييلات العدوانية لديهم، بالإضافة إلى دراسة ميلر

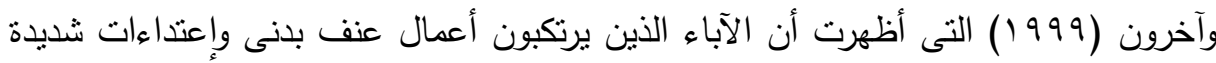

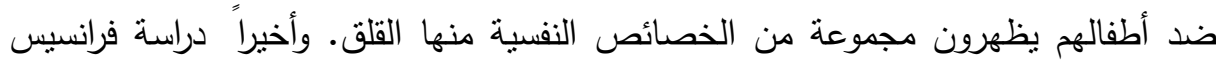

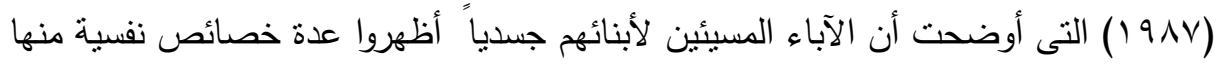

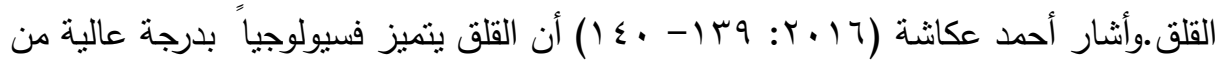

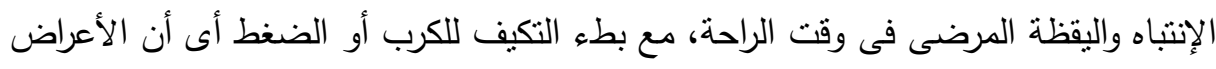

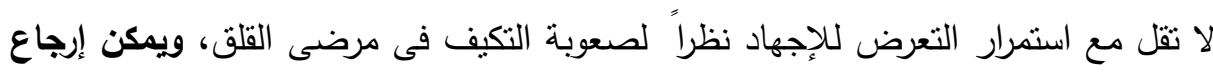
هذه النتيجة للأسباب والعوامل الأتية: هالإلتزامات والأعباء المادية التى يتحملها الرجل كمسؤول أساسى عن تلبية إحتياجات الأسرة تزيد من نسبة القلق لديه. • طبيعة النقافة فى المجتمع المصرى التى تلقى على رب لتى الأسرة مسؤولية زواج الأبناء وتوفير فرص عمل لهم خاصةً الذكور ، وما يتطلبه ذلك من توفير إمكانات مادية للأبناء وقد تمند فى بعض الأسر إلى المشاركة فى توفير بعض المنطلبات المادية للأحفاد.

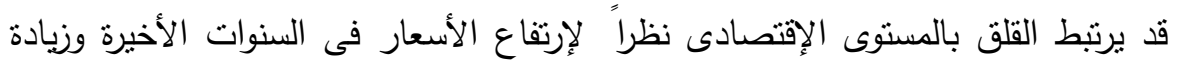
معدل التضخم، مما أدى إلى زيادة الأعباء المادية على رب الإنى الأسرة.

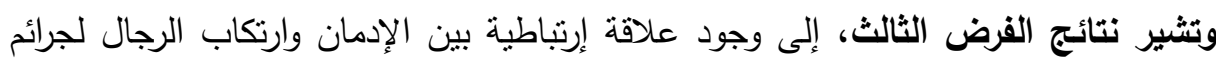
القتل داخل الأسرة، وتتفق هذه النتائج مع دراسة ميلر وآخرون (1999)التى أظهرت نتائجها أن الآباء الذين برتكبون أعمال عنف بدنى وإعتداءات شديدة ضد أطفالهم يعانون من بعض دأل

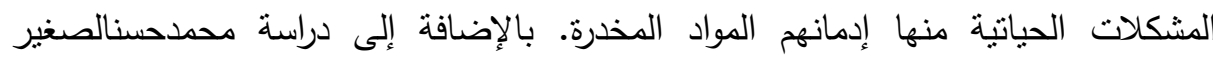
(Y (Y) التى بينت نتائجها عدة أسباب للعنف الأسرى فى المجتمع السعودى منها إدمان 


\section{تروسيامت التوراسما}

توصى الدراسة الحالية فى ضوء نتائجها ما يلى:

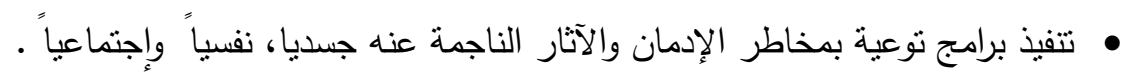

• • ت تغليظ العقوبة الخاصة بتعاطى المواد المخدرة أو الإتجار فيها.

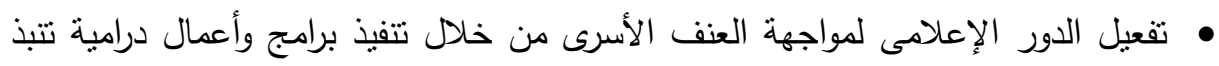

العنف وتتتاول أنماط النتشئة الإجتماعية السوية.

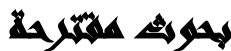

• تأثثر الأعمال الدرامية التى تحتوى على مشاهد عنف على ارتكاب العنف فى الأسرة

$$
\text { المصرية. }
$$

• أثر العوامل الثقافية على ارتكاب جرائم القتل فى صعيد مصر •

• دور الأسرة النووية والأسرة الممتده فى ارتكاب جرائم القتل داخل الأسرة "دراسة مقارنة".

\section{المرالئ}

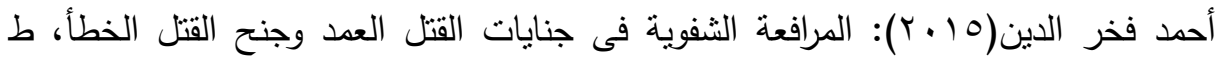

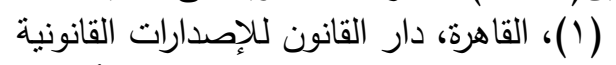

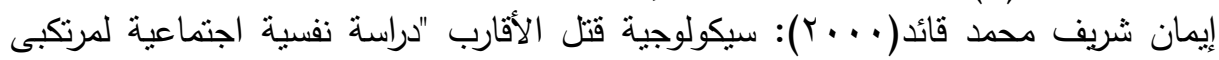

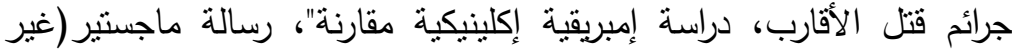

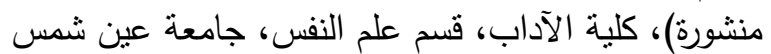

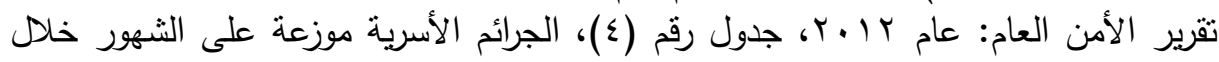

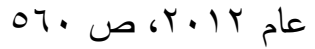

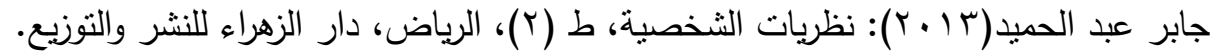

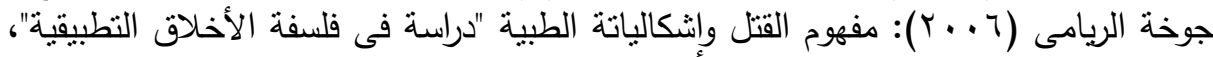

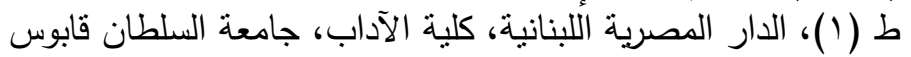

رشاد عبد العزيز، زينب العايش(9 . . ץ): سيكولوجية العنف ضد الأطفال، ط (1)، القاهرة،

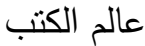

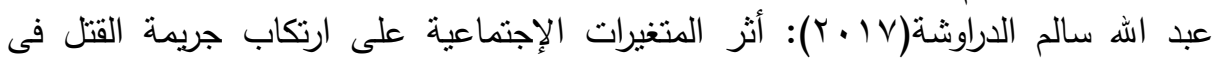

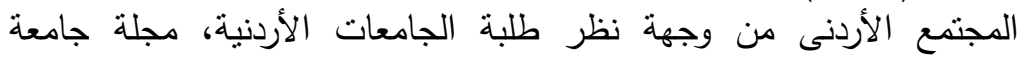

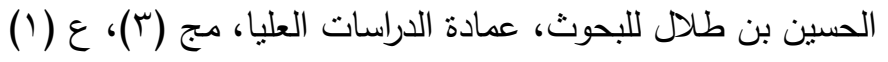

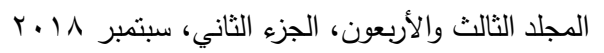




$$
\begin{aligned}
& \text { على عبد السلام على( . . ؟ ): أصول علم النفس الجنائى وتطبيقاته العملية، ط ( ()، القاهرة، } \\
& \text { مكتبة النهضة المصرية }
\end{aligned}
$$

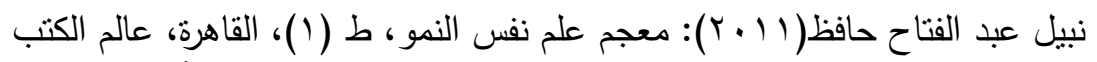

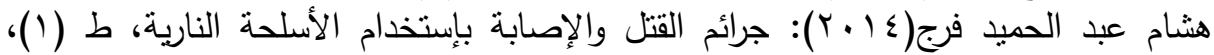

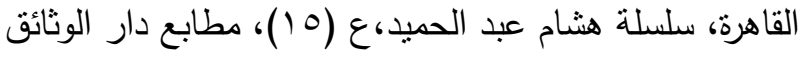

Hanlon, Robert E; Brook, Michael; Demery, Jason A; Cunningham, Mark D: Domnestic homicide. (2016): Neuropschological profiles of murders who kill family members and intimate partners, Journal of Forensic Sciences. Vol. (61), Jan, P.P S163-S170.

Sorensen, Jon; Cunningham, Mark, D. (2010): Conviction Offense and Prison Violence: A Comparative Study of Murderers and Other Offenders, Crime \& Delinquency, Vol. (56) N (1) p103-125.

\title{
SOCIAL AND PSYCHOLOGICAL VARIABLES ASSOCIATED WITH MALE MURDERING CRIME OFFENDERS IN FAMILY AN APPLIED STUDY ON EGYPTIAN PRISONS
}

Abd El- Meneam, Olaya, M. ${ }^{(1)}$; Ahmed, G. S..$^{(2)}$; Hussien, M. A. ${ }^{(3)}$ and Hany, A. F. ${ }^{(1)}$

1) Institute of Environmental Studies \& Research, Ain Shams University 2) Faculty of Post Graduate of Childhood, Ain Shams University 3) Faculty of Arts, Damietta University.

\begin{abstract}
The purpose of this study was to shedding light on the crimes committed by men against their family members and identifying the social and psychological variables associated with them, as well as 378

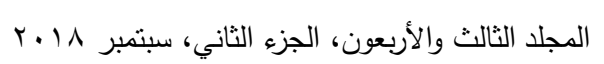


determining the demographic characteristics of these men. The researchers followed the comparative descriptive approach. The total sample of the study consisted of (150) wives from the men who were deposited in the Turaprison and their ages ranged between (21-70) years. The researchers used the following tools: State-Trait Anxiety Inventory (STAI) (Abdulraqeeb $\mathrm{El}$ Behairy), The Minnesota Multiphasic Personality Inventory (MMPI) (Luis Melika et al.),Initial data form (researchers), Case study form (researchers). The results of the study indicate that there is no effect of the social variables represented (age, occupation, educational level, economic level, size of the family) on the murder of men within the family at a significant level (0.05), the absence of significant differences at a significant level (0.05) Between the mean scores of the sample of the study on the (MMPI) test depending on the social variables of age, occupation, educational level, economic level, size of the family. The study showed statistically significant differences between the mean scores of the study sample on the (STAI) test and the level of anxiety of adults according to the variable of the economic level, and the social variables of age, occupation, educational level, and family size did not affect the men who committed the murders within the family. The results of the study also showed a correlation between addiction and men committing murder within the family. 